\title{
Making the mundane remarkable: an ethnography of the 'dignity encounter' in community district nursing
}

\author{
Emma Stevens $^{1,2 *}$ (D), Elizabeth Price ${ }^{1}$ and Elizabeth Walker ${ }^{1}$ \\ ${ }^{1}$ Faculty of Health Sciences, University of Hull, Hull, UK and ${ }^{2}$ Faculty of Wellbeing, Education and \\ Language Studies, Open University, Walton Hall, Kents Hill, Milton Keynes, UK \\ ${ }^{\star}$ Corresponding author. Email: DrEmmaStevens@gmail.com
}

(Accepted 28 April 2021; first published online 8 July 2021)

\begin{abstract}
The concept of dignity is core to community district nursing practice, yet it is profoundly complex with multiple meanings and interpretations. Dignity does not exist absolutely, but, rather, becomes socially (de)constructed through and within social interactions between nurses and older adult patients in relational aspects of care. It is a concept, however, which has, to date, received little attention in the context of the community nursing care of older adults. Previous research into dignity in health care has often focused on care within institutional environments, very little, however, explores the variety of ways in which dignity is operationalised in community settings where district nursing care is conducted 'behind closed doors', largely free from the external gaze. This means dignity (or the lack of it) may go unobserved in community settings. Drawing on observational and interview data, this paper highlights the significance of dignity for older adults receiving nursing care in their own homes. We will demonstrate, in particular, how dignity manifests within the relational aspects of district nursing care delivery and how tasks involving bodywork can be critical to the ways in which dignity is both promoted and undermined. We will further highlight how micro-articulations in caring relationships fundamentally shape the 'dignity encounter' through a consideration of the routine and, arguably, mundane aspects of community district nursing care in the home.
\end{abstract}

Keywords: older adults; gerontology; ageing; dignity; community nursing; district nursing; ethnography; relational care

\section{Introduction}

The care of older people in the United Kingdom (UK) has demonstrated a significant movement away from hospital-based care towards community health-care models (Temmink et al., 2000; Markel-Reid et al., 2006), yet financial resources have not necessarily accompanied this policy-driven shift (Charles et al., 2018). Community nursing, then, takes place within the discourse and experience of 
increasing demand and diminishing resources. The concept of community nursing itself is an umbrella term used to describe an extensive range of nursing activities, including "any nursing care delivered "outside" the hospital setting, such as patients' homes, or residential care or health centres' (Spilsbury and Pender, 2015: 129). This type of care accounts for 100 million patient contacts annually, $£ 10$ million of the National Health Service (NHS) budget and one-fifth of the NHS workforce (King's Fund, 2019). In the UK, district nurses provide a very particular type of community nursing care-specifically nursing care in people's homes where it is recognised that a significant proportion of their work involves older adults (Cornwell, 2012; Maybin et al., 2016; Dixon and Thompson, 2018; Quaile, 2018). It is the home nursing care experiences of older adults and the staff within a community nursing team with which this paper is concerned.

Community nursing practices are often obscured, being undertaken 'behind closed doors' in a public-private space, into which 'outsiders' are rarely granted access, yet the homes of older adults remain an important location for care delivery (Twigg, 2000; Dyck et al., 2005; Milligan, 2009; Maybin et al., 2016). We argue that an exploration of community nursing practices offers an opportunity to observe and analyse the practices and relationships that occur in this, often unseen, clinical context. It is this 'home space' which constitutes one of the key analytical tools we employ in this paper. We understand the home as a complex relational space in which relationships are developed, performed and negotiated (Cloutier et al., 2015). Our overarching concern is to demonstrate that dignity is filtered through and by the micro- and macro-relational contexts in which the boundaries of clinical and non-clinical working spaces are profoundly blurred.

As we will demonstrate, dignity, when present, often remains unacknowledged; it is only when dignity is challenged or violated that its absence is likely to be identified and addressed, akin to Arendt's (1958) 'paradox of human rights' in which rights are taken for granted when upheld but only become noteworthy when contravened. We suggest that it is in the mundane contexts of the home space and within the routine, and often un-noteworthy, practices of nursing interactions that dignity is embedded, taken for granted and often invisible. It is in these contexts that we invoke the 'dignity encounter', a term we use to describe an interaction in which dignity is co-constructed in the day-to-day work of community nursing. The 'dignity encounter', we argue, can offer important insights into the concept of 'dignified' care (Nettleton et al., 2005; Buse et al., 2018).

In the context of community nursing care, dignity is mediated and displayed in aspects of relational care between nurses and older adults. It is in these microrelational contexts where the 'dignity encounter' is constructed. It is in the context of scrutinising some of the ostensibly mundane and unremarkable care practices with older adults that it is possible to elucidate the nature, and everyday manifestations of, the 'dignity encounter'.

\section{Conceptualising dignity in community nursing}

Dignity is a complex concept; hard to define and measure (Fenton and Mitchell, 2002; Tranvåg et al., 2016). It has been variously described as 'useless' because, aetiologically, 
it has no greater meaning than respect for autonomy (Macklin, 2003: 1419). Yet, it has also been referred to as a 'rich and powerful concept' (Michael, 2014: 13).

Notions of dignity have been widely considered from many perspectives. Kant (17241804), for example, firmly located dignity in the wider concepts of morality and autonomy, recognising that, by virtue of being human, each person has intrinsic worth, and, therefore, an inherent dignity. Beyond this fundamental proposition, however, the ways in which dignity is socially constructed and operationalised varies markedly.

In the specific context of dignity and older people, Nordenfelt $(2004,2009)$ developed a model conceptualised around four discrete 'types' of dignity: 'dignity of merit', which applies to people who have gained a higher status or rank, potentially due to their social position; 'dignity as moral stature', linked to self-respect and remaining dependent on the thoughts, actions and deeds of the subject; 'dignity of identity', being the subject's self-respect, which can be influenced by their interactions with others; and, finally, Menschenwürde which is the inherent worth of people, closely allied to Kant's concept of inherent dignity.

Despite the contested nature of dignity, it constitutes an important principle of the global health movement (Horton, 2004), framing policy and guiding practice and ethics in contemporary nursing care (Kalb and O'Conner-Von, 2007; Hewison, 2011; McDermott-Levy et al., 2018; Mullen et al., 2019). Many conceptualisations of dignity are, though, rhetorical (Johnson, 1998), offering little practical guidance in the context of the care of older people (Agich, 2007; Barclay, 2016). In health-care contexts, dignity is obviously threatened by the occurrence of illness or disease (Raee et al., 2017), yet people can maintain their dignity when requiring support if they are enabled to live in accordance with their own standards and values (Barclay, 2016). Dignity is, of course, potentially upheld in the context of home health care, but, for older people in particular, this is also the place where it is most fundamentally threatened. For people who may be subject to multiple, and increasing, relationships of care and support, these possibilities and threats are most profoundly felt and experienced (Lloyd et al., 2014). Thus, older people can be simultaneously empowered by health-care interventions (which enable them to continue to age in place, maintain their relationships and decision-making powers, and retain autonomy and control) whilst being, simultaneously, at risk from potential compromises to their personal agency and autonomy, brought about by ineffective, undignified and disrespectful care practices. It is, most importantly, the relational aspects of care thatsit at the heart of this paradox and which are central, and critical, to ensuring dignified nursing interventions and care and, ultimately, to creating positive health outcomes for older people (Martin-Matthews et al., 2013; Cloutier et al., 2015; Tranvåg et al., 2015; Šańáková and Čáp, 2019; Clancy et al., 2021).

Dignity more broadly has been explored in relation to health care, however, this has been primarily focused on experiences within acute, in-patient or residential settings where older people are recognised to be at risk of losing their dignity in institutional contexts (Franklin et al., 2006; Høy et al., 2007; Baillie, 2009; Webster and Bryan, 2009; Tadd et al., 2011a, 2011b; Hall et al., 2014; Rehnsfeldt et al., 2014; Šaňáková and Čáp, 2019).

Therefore, the experiences of older adults receiving community district nursing care have not been as widely considered (e.g. Lundgren et al., 2011; Holmberg et al., 2012). Black and Dobbs (2014: 1292) recognise, in particular, that 'little research has been conducted into the meaning of dignity to community-based older adults 
in the context of everyday life'. Therefore, whilst it is possible to draw upon the extant experiences of older adults in institutional contexts, this paper contributes additional insights into the dignity practices in the home space.

\section{Methodology and methods}

\section{Study design and methods}

An ethnographic approach comprising fieldwork of 470 hours incorporating detailed observations $(\mathrm{N}=62)$ and individual interviews $(\mathrm{N}=22)$ enabled close examination of community nursing care practice in older people's homes. Fieldwork was conducted for a total of 14 weeks between July and October 2017.

Sixty-two clinical interactions were observed, lasting from 15 minutes to over an hour, and involved nurses $(\mathrm{N}=13)$ and older adults aged between 60 and 94 years $(\mathrm{N}=40)$. In week 8 , following seven weeks of observations, semi-structured interviews commenced (in addition to observations) and continued until fieldwork ceased, eight weeks later. Interviews were undertaken with clinical staff $(\mathrm{N}=11)$ and older adults $(\mathrm{N}=11)$. Older adult interview participants were both male and female, aged between 60 and 93 years, all of whom had previously been observed. The interviews offered the opportunity to explore participants' experiences of previously observed clinical encounters. Questions included:

- What does dignity mean to you?

- Can nurses affect older adults' dignity? How?

- What helps to promote dignity?

- How would you define good care?

\section{Inclusion criteria}

The inclusion criteria for the staff sample were:

- Aged 18 or older.

- Delivering care in the community nursing team (incorporating registered nurses and unregistered health-care assistants).

- Willingness to be involved in the study.

The inclusion criteria for the older adult sample were:

- Aged 60 or older.

- Under the care of the community nursing team.

- Mental capacity and willingness to consent to involvement in the study.

- Not living in residential care.

- Ability to communicate in English.

\section{Recruitment}

The purpose of the research was first presented at a district nursing team meeting during which all staff were given a participant information leaflet. Consequently, individual staff members volunteered to take part. The job roles of staff-participants spanned six clinical 
gradings, known as 'bands', which reflect their level of training, responsibility and remuneration, with the higher bands being the more senior staff. Participants included: health care assistant (bands 2 and 3), bank nurse (band 5), community staff nurse (band 5), case manager (band 6), district nurse (band 6) and complex case manager (band 7). Health care assistants were non-registered clinical staff and the term 'district nurse' could only be used by nurses that had undergone post-registration training that enhanced their nursing specialism to lead care in the home (Morris, 2017). Once staff members had consented to participate, they acted as gatekeepers for older adults in their care, determining older adults' eligibility for inclusion (based on the aforementioned inclusion criteria), hence this element of recruitment remained out of the direct control of the researchers. In advance of the ethnographer's first visit, each nurse gained verbal consent from each older adult. At the initial visit, the ethnographer gained written consent to participate, and ongoing verbal consent was sought at each subsequent visit. There were no direct benefits for participants, and no incentives or rewards were offered.

\section{Methodological reflections}

Ethnography was judged to be the most appropriate methodology to explore how dignity manifests in the nursing care of older adults in their homes, and the methods enabled rich data to be triangulated from a combination of observations and interviews. These methods relied on the ethnographer building trusting relationships with participants, and therefore some reflexivity on the operationalisation of the methodology requires acknowledgement.

Ethnographies can be approached from an 'insider' or 'outsider' perspective (Taylor et al., 2015), or the non-binary position of being 'betwixt and between' (Turner, 1967: 93). The person undertaking fieldwork in this project held a role within the host organisation as a social worker tasked with safeguarding vulnerable adults in the local community, and although she had never been based with the team being observed, she had previously established professional relationships with some members of the team. Adler and Adler (1987) identified the three roles of observational researchers: peripheral, active and complete, and, in this context, the ethnographer identified as being peripheral and 'betwixt and between'. This position enabled the development of trusting relationships with staff-participants. In this context, reflexivity was integral to the research process whereby the dual role of ethnographer/staff member was a regular point of reflection and the reflective diary provided essential insights into the ethnographer's positionality which informed an important aspect of the process of data collection, interpretation and analysis.

The quality of ethnographic research depends on the ethnographer creating trusting working relationships with participants, and when conducting observations, the observer must recognise that simply by being present they are influencing the interaction that unfolds. Remaining mindful of these influencing factors were also elements of the reflexive process.

\section{Ethical approval}

Ethical approvals for the study were received from the University of Hull, Faculty of Arts and Social Sciences, and Yorkshire and the Humber - South Yorkshire NHS Research Ethics Committee (Ref: 17/YH/0009. IRAS ID: 21677). 


\section{Data analysis}

Analysis followed the six phases of qualitative data analysis identified by Braun and Clarke $(2006,2013)$. All interviews were transcribed verbatim, ensuring they were 'thorough and of high quality' (Braun and Clarke, 2013: 162). All fieldnotes/reflexive journals, observational data and interview transcripts were stored on QSR NVivo where 'complete coding' (Braun and Clark, 2013: 206) took place. Codes were a combination of 'data-serviced codes' and 'researcher-derived codes' (Braun and Clarke, 2013: 207), which ensured codes emerged from the data (data-derived codes), examples include: self-management of health conditions, pain management, healing (bandages and dressings); alongside the development of interpretations (researcher-derived codes), e.g. emotional labour, nurse as friend, nurse as expert. The study's trustworthiness was regularly evaluated in line with Guba (1981).

\section{Study location}

This study was based in a community nursing team located in an urban area of northern England. Using the Index of Multiple Deprivation, the city is ranked within the top five most deprived local authorities in England (National Statistics, 2019).

The host organisation offers more than 80 diverse health services in a range of urban and rural locations across the north of England. Data collection occurred within one of the organisation's three urban community (district) nursing teams. Older adults accessed their services if they were registered with a general practitioner (GP) within their specific geographical area and they were unable to leave their home to attend appointments in a health centre and thus required nursing care in situ.

\section{Findings}

Direct quotations from interviews include a pseudonym and the prefix 'Nurse' has been applied when the participant was a staff member. Although staff-participants included registered and non-registered clinical staff, the generic terminology of 'nurse' has been adopted to aid in maintaining participants' confidentiality. Names without a prefix are older adult-participants and their age follows their pseudonym. Ethnographic observations have been italicised and written reflexively in the first person.

Three key themes arising from the data will now be considered in more detail: dignity in relationships, embodied dignity and dignity in the home.

\section{Dignity in relationships}

Using ethnographic observations and interview data, we will now consider how the 'dignity encounter' is co-created in the relational care space between community nurses and older adults.

\section{Negotiating dignity}

I think dignity is terribly important. It's helping the disabled person in the hospital bed to be clean, washed, hair combed and sat up, so that they've got some self- 
respect. And they get their dignity back. Rather than just leave them lying there in squalor. And then again we come back to the nurses, don't we? 'Cos them nurses need to realise that. (Jack, 81)

Jack remained seated on his sofa as District Nurse Claire manoeuvred into position at his feet before starting to create a sterile field, which is the aseptic space required to reduce risks of infection during clinical interventions. Meanwhile, Jack spoke about his holiday plans, and his passion for cars as Claire listened intently, engaged in the conversation, and paid little conscious attention to creating the 'sterile field', spreading packaged dressings seemingly haphazardly, whilst focusing her attention on Jack's words. Claire's demeanour changed from being haphazard as she very carefully began to gently unwrap the bandage from around Jack's leg.

Under and over; under and over; under and over. Quietness ensued as she meticulously unwound the outer dressings. After removing the bandages, she discarded her soiled gloves to one side, replacing them with a clean pair, before she interrupted the silence with a formal question:

'Are you experiencing any pain in your leg?'

'Yes - right here.' Jack pointed.

The quietness resumed as Claire slowly began re-bandaging Jack's leg, whilst he silently looked on. Once finished, Claire picked up Jack's nearby drug card, checking what pain relief had been prescribed.

'That's quite a lot!' she exclaimed, before continuing, 'As you're still in pain, I'll speak to the GP for a medication review.'

Jack nodded. 'Can you get my socks that are drying on the radiator in the hallway?'

Claire left to oblige.

Jack turned towards me, 'When you start dropping your standards, that's when your dignity goes.' (Jack was a retired military man) 'Standards are dropping terribly,' he continued. 'The whole world revolves around standards'.

Claire returned and began placing a sock on the foot of Jack's newly dressed leg.

'That's better!' Jack confirmed as Claire settled herself back onto the floor to continue working on his other leg.

This was the only occasion Jack and Nurse-Claire were observed together, but, their positive working relationship was amply apparent. This was a routine, unremarkable interaction, but the unexceptional content of their encounter contributed to its inherent dignity, which was marked by long, comfortable, silences, by Claire's smiles and questions about Jack's holidays, and by the careful, tender bodywork with which she engaged whilst undertaking the leg dressings. Jack had clearly defined expectations of the role nurses play in maintaining dignity, but, here, his reference to the hospital setting is illuminating, as it frames his understanding of what constitutes dignified care. However, in the context of care at home, dignity is not manifest only in the clinical task (exemplified, in this scenario by the 'sterile field'), it is implicitly shaped in the relational aspects of Jack and Claire's interaction. Moreover, it is the home space that foregrounds and facilitates the centrality, and very particular intimacy, of the relational context of care practices. 
During his interview, Jack was asked to reflect more widely on this care episode. He noted:

Claire [nurse] was dignified because she's got self-confidence, she knows exactly what she's doing. I was dignified because I was treating her with respect. (Jack, 81)

This quote offers an illuminating example of how dignity is created in the relational spaces between nurses and older adults. It highlights how, for Jack, the nurse's display of self-confidence reflected her dignity, but, for Jack, his own dignity was contingent on the way he reflected this dignity back in his treatment of his nurse (i.e. with respect). According to Jack, Claire gained dignity from within, but he gained it externally as a result of his outward displays to the nurse, ensuring his dignity was contingent on his own behaviour towards his nurse, whereas her dignity manifest internally from the knowledge and nursing skills she demonstrated in practice. Jack perceived Claire as dignified, as she knew her trade and performed it well. Therefore, in this context, the 'dignity encounter' is shaped by the social features of the relationship - negotiated understanding of care practices:

You can get people ... you know they don't care. But nurses are different. They seem to have a dedication. Er ... they ah, you just feel right when they're there with ya. (Jack, 81)

Jack's quote illustrates the intangible nature of dignity, but, it is clear that, for him, it manifests in terms of an emotional response to a professional persona. The 'dedication' Jack refers to includes the tacit knowledge, the skills, values, attitudes and approaches nurses adopt with older adults in order to co-construct a 'dignity encounter'. Conversely, of course, if an older adult is not comfortable in their relationship with their nurse, dignity may be rendered fragile in their exchanges and there are, then, increased opportunities for encounters that have the potential to undermine dignity.

As in Jack's case, it is not necessarily the clinical intervention per se that influences experiences of dignity. Instead, for older adults, dignity manifests in terms of their feelings through their relationships with nurses, as described below:

Well to me personally they [nurses] treat you as a person. They don't treat you as someone just laid there and they're doing their job. They have a little chat with you, they make you feel so much better, just by chatting. (Alison, 82)

When I'm talking to 'em [nurses] I don't feel as old as I am. Or as old as I look, I just feel ... all right inside. They are very, make me feel like, like they should. That I'm, you know, I'm the one when they're here and they're doing everything for me. (Antonia, 83)

[Nurses] make you feel so comfortable. (Don, 71)

These respondents thus experienced dignity as embedded in the emotional responses manifest in their relationships with nurses, leaving them feeling valued, cared for and acknowledged. Conversely, as illustrated in a quote from Antonia, dignity can be swiftly undermined when relationships fail to create these positive, validating responses: 
One time I think I told her [the nurse] about something and she said, [sharply]

'I know what I'm doing.' So, to me that was a real blunt reply. (Antonia, 83)

It is the micro-articulations of language, movement and behaviour that can disrupt, or indeed, aid, the construction, and experience, of dignity. As was the case for Antonia, it may not be the actual words spoken, but the vocal tone that can disrupt the flow and quality of the relationship and significantly undermine the possibility of a 'dignity encounter'. The 'dignity encounter', therefore, can be construed as actively co-created in the micro-moments of interpersonal space.

Illustrating how emotional responses can enhance dignity after (as well as during) a relational interaction, Jack explained the nurses' different approaches, also highlighting how clinicians and older adults may perceive dignity outcomes from different perspectives:

Jack (81): $\quad$ Some of them [nurses] are extremely ... old hat. If you know what I mean.

Interviewer: Tell me what you mean.

Jack: $\quad$ Starchy ... er, professional nurse. Er ... nothing wrong with it ... old school. They do things the established old way ... Then you get some nurses that are really laid back ... and er, they have a softer approach. But all in all, all of them do the job in their own way and they achieve the result which is what matters.

Interviewer: Okay. So for you, it's more about, not how they do it, but about the result at the end?

Jack: I think that's most important. And I think, think this is the nub of the matter. It's the end product that matters.

Interviewer: What's your end product then?

Jack: $\quad$ Feeling good after they've gone. And I always do. They always manage to, ugh, they always manage to lift me.

Jack created a nurse typology: 'professional', 'old hat', 'laid back' and 'softer'. Yet, for him, it was not the different approaches that influenced his dignity. Rather, it was the 'end product' (his feelings once the professional encounter was ended). Jack did not link his 'end product' to the physical care that he received, but he expressed it as experiencing positive feelings within relational aspects of his care; a much 'softer' and profoundly intangible goal, in contrast to those of nurses and other medical professionals, whose expectations of an 'end product' are more likely to be healing or curing:

We are here actually to try and heal that wound that's my ... my mission, that's my goal to get you healed and discharge you. (Nurse-Ivy)

Things like wounds we need them to sort of heal the quickest possible. (Nurse-Sheila)

If we went in and somebody had a skin tear I might immediately be thinking about how to heal and treat the leg. (Nurse-Mary) 
In this context, it is healing, rather than the 'dignity encounter', that remains the main focus of the nurses' work, which highlights the disparate ways in which older adults and clinicians may understand, evaluate and prioritise the 'dignity encounter'.

\section{Embodied dignity}

The 'dignity encounter', of course, takes on various guises. The body itself, for example, can be a crucial mediator of dignity when community nurses deliver care. This is nowhere more apparent than when bodies misbehave. At these times, the body, particularly the ill body, can disrupt dignity. Ill and 'out-of-control' bodies can be a source of shame, as they may not externally present as anticipated, or desired, nor behave within the parameters of the usual standards of social acceptability. Critically, within the theme of 'embodied dignity', this research identified that both continence and bodily odours are important mediators of dignity for older adults, yet the importance of these are not necessarily recognised by clinical staff. One exception to this was Anya.

\section{Anya's 'passion': 'Nobody should be wet'}

When I get a message saying, 'you've changed my life, I'm now going out, I was dry, I didn't have any worries'. To me, [that] is the best care and the best feedback I could possibly get. If we get good continence, we relieve a lot of pressure on other services because they're not falling, because they're not rushing, because they're confident, less infections, [reducing] social isolation, they become more independent. But we don't give it its credit, we don't give continence the importance. I think a lot of nurses go, 'oh, it's only continence, put it to the back-burner', but actually, no ... to that patient it should be treated it's exactly the same as ... a leg, a wound, a blood, because to that person, it's the most important thing ever. (Nurse-Anya)

Poppy, aged 79, had been referred to Anya for an incontinence assessment. We sat in her conservatory overlooking her garden whilst Anya asked Poppy some general questions, such as her age, existing health conditions, and generic supplementary questions, noting down the responses. As they spoke, Poppy's husband avoided eye contact whilst slowly moving between the kitchen and garden, which involved walking past our seats in the conservatory to gain access to both areas.

In anticipation that he may at any point appear again, Anya lowered her voice to forewarn,

'The next three to four questions are quite personal'.

Poppy nodded.

Silence.

Anya paused to allow Poppy's husband sufficient time to move back through the conservatory. Once Poppy's husband had returned to the garden, Anya enquired

'Do you have any discharge?'

'Erm ... No.'

Almost on cue, Poppy's husband moved back past us in the conservatory and entered the kitchen. Anya remained silent, scowling at the paperwork on her lap.

The assessment slowly continued as Anya interspersed questions around the man's movements, and, from Poppy's responses, more questions ensued,

'Do we wet our knickers?' 
'No,' replied Poppy.

'Do we need to change any of our underwear?'

'No.'

'Do we wet the bed?'

'No.'

Anya's choice of language in this exchange is particularly noteworthy - the use of the word 'we', in particular. In her interview, Anya was invited to reflect on this issue:

I don't want anyone ever thinking they are alone, 'cos they're not alone, lots of people wet their knickers you know. I didn't realise I'd said it, but ... I don't ever want anyone thinking they're in isolation, that they're the only person. We shouldn't be embarrassed about it. It's not something we have to hide. Nobody should be wet. (Nurse-Anya)

From her perspective, the use of the word 'we' was indicative of Anya's attempt to be inclusive in her discussions around 'wee', despite it having the potential to appear simultaneously infantilising or patronising. Several observations were undertaken with Anya doing what the nurses described as 'inco-visits'; terminology which itself emphasises the body's inability to control the release of waste matter ('incontinence' = dignity-reducing), rather than focus on the person's ability to contain waste ('continence' = dignity-enhancing). Arguably, any reference to continence in this context has the potential to undermine dignity.

An understanding of the importance of continence work was not, however, universally shared by Anya's senior colleagues, who regularly requested she prioritise other tasks, but Anya argued:

No, you're not taking my continence visits off me, I'll manage them, you know, I'll do your leg dressing but ... I'm still gonna go and do this [incontinence assessment]. (Nurse-Anya)

As a health-care assistant, Anya's role was positioned relatively low down the nursing hierarchy. She explained:

[Health-care assistants are] this little entity that goes out and the does all their [the nurses] ... shitty jobs, the more shitty jobs sometimes. (Nurse-Anya)

However, the 'dirty work' that Anya described as 'shitty' remained fundamental to older adults' dignity, ensuring so-called lowly work remained towards the top of what might be termed a 'dignity hierarchy'. When successful, Anya was able to reconcile the conflict between the odours associated with continence problems and an associated loss of dignity by enabling access to resources that would restrict the flow of urine, which, in turn, reinforced dignity through the presentation of a clean and socially acceptable body. Anya's 'passion' for continence remained closely aligned with participants' concerns around smells and dignity, as worries about malodour 
were echoed by many older adult participants, who also regarded it as dignity-reducing:

I used to go visit an old lady and she used to say, 'you promise me Barbara, as soon as I smell, you'll tell me' and I, I do this meself [sic] now. (Barbara, 77)

I always want perfume so I can make myself smell nice because I know you don't always smell nice when you're not very well. (Antonia, 83)

Lizzie provided an illustration of compelling connections between continence and dignity. The nurses described Lizzie as 'a palliative patient, refusing treatment', language that effectively reduced her to a problematic 'refuser'. Before her retirement, Lizzie held a senior nursing role in a national organisation and, at 91 years old, she regularly voiced contentment with her life. Lizzie's self-management of her own health needs signalled the expression of her own agency and control over how she wanted to experience dignity. This was also reflected in her refusal of any treatment for cancer, which she perceived as degrading and undignified, explaining:

You're born with dignity and, my God, you should die with dignity. (Lizzie, 91)

During our first observation, Lizzie proudly declared,

'If I need something, I will buy it!'

Lizzie used this as a justification to Anya for buying 'incontinence pants' from her local chemist. Despite Anya's explanation that she was entitled to free incontinence pads, Lizzie protested that she never had anything for free from the National Health Service and,

'I do not need anything free now!'

Anya patiently listened whilst Lizzie shared her views and then when there was an appropriate opportunity, she asked,

'So, how have you been getting on with the [incontinence] pads I gave to ya?'

Lizzie described how she wore her own incontinence pants from the chemists and placed Anya's incontinence pads inside them.

Anya grimaced before she clarified to Lizzie that there was no need to buy pants as the pad could go directly in her knickers and 'do the same job'. Anya explained this to Lizzie in at least three different ways. Each time Lizzie's reply remained constant,

'Yes, but I don't want to smell!'

After several iterations of this statement, and perhaps as a response to her frustration, Lizzie turned to me and barked,

'You've been near me - do I smell?'

Fortunately, I was able to quickly offer an honest and reassuring response.

'No, you don't smell.'

Lizzie grinned in the satisfaction that these words essentially confirmed the effectiveness of her 'double-padding' approach to continence care.

Anya remained undeterred,

'My pads have something in them that just draws in the urine, so it won't leak and won't make it smell. So, you don't need to buy any more pants.'

'But I don't want to smell. That's why I sometimes wear the pads, pants and my 
knickers. I've changed my knickers twice today already.'

I glanced at the clock. It was 11:20 am.

Anya continued,

'You won't smell and you don't need to change your knickers so often. My pads draw in the smell.'

Their conversation had reached an impasse.

Lizzie had taken control of her own continence care, managing it in a manner that enabled her to maintain her own standards of dignity. Anya's persistent attempts to persuade Lizzie to use the incontinence pads in accordance with the instructions expressed an underlying clinical view that failed to recognise Lizzie's subjective experiences of (in) dignity. Anya's view was based solely on the clinical effectiveness of the treatment on the physical body, without acknowledging Lizzie's embodied agency, which may operationalise dignity in a different manner, highlighting a potential conflict between medical knowledge of the effective treatment of the body as an object and the person's own experience of dignity, as these may not be mutually dependent. As a retired nurse, Lizzie must have previously adhered to the foundations of her profession, grounded in western medical 'evidence-based' clinical knowledge of effectiveness. Yet now, in the context of her own bodily experience, she asserted her own agency, prioritising her subjective dignity over medical 'evidence', thereby managing dignity in her own way.

\section{The body and dignity}

Brenda was described by the nurses as 'bed-bound' and on our arrival her husband invited us into their bedroom, where he remained during the appointment. As part of her assessment, Nurse-Nieca asked to check Brenda's pressure areas. Brenda quickly lowered her pyjama trousers, fully exposing her bottom. After glancing at Brenda's semi-naked body, Nieca was satisfied there was no indication of pressure damage and therefore began typing-up her observations. Brenda remained silent on the bed, with her bottom on view whilst her husband spoke to the nurse, and I focused my eyes on Nieca. After what felt like an eternity, but what must have only been perhaps a minute or two, Brenda's husband told her it was 'all right' and she could cover herself.

Brenda's exposed bottom was necessary to check the pressure areas, however, as Nieca began typing her notes without further observation, the length of exposure appeared unnecessary, making a transgression of dignity possible. In this scenario, the participants all appeared to normalise an objectified body as something that required observation and assessment, which, it was presumed, did not have an influence on the dignity of the person in question. Indeed, when nurses and older adults enact shared/presumed standards such as these, dignity violations are unlikely to be labelled as such during the enactment of normalised behaviours - transgressions of dignity are more likely to be identified when people hold contrasting views.

Embodied dignity is also reflected in the intersection between body and space, as illustrated by Barbara, whose personal and social identity was married to her use of prosthetic legs.

Barbara was 77 years old and had been receiving daily insulin injections from the community nurses for over three years. Both her legs had been amputated, and it 
was her (lack of) legs that remained central to her creation of 'dignity encounters'. Barbara regarded disability as something that evoked pity from others and through maintaining a sense that her body was complete, felt able to avoid this reaction from others:

[I] just keep smiling all the time. When I talk to people I just talk to 'em like I've got my legs, just natural. So I never let them know. (Barbara, 77)

For Barbara, missing legs were a source of shame and potential stigmatisation. Maintaining a façade of bodily wholeness enabled her to maintain her preferred sense of self and an undiminished social and personal identity. In this context, Barbara's prosthetic limbs were not purely replacements for her lost legs, but symbolic indicators of completeness and dignity. Paradoxically, however, during observations Barbara expressed disgust towards her prosthetic legs. Barbara wanted new prosthetics, describing her existing legs as 'horrible', as they were uncomfortable, despite being superficially visually appealing:

When they made them I said, 'make sure you put me slim ankles', so when I'm in a wheelchair you think I've got me legs, proper legs. (Barbara, 77)

To maintain her dignity, Barbara did not want other people to identify her legs as 'fake'. She explained:

When I'm out people don't realise they're fake legs, so when I'm in my wheelchair they don't stare and make me feel like everybody else. (Barbara, 77)

For Barbara to experience dignity, she wanted, not to be viewed as exceptional, but to be regarded the same as 'everybody else', which she achieved by concealing her difference. Despite her prosthetic legs, Barbara required a wheelchair to mobilise, but, importantly, this did not elicit the same negative reaction from her. Although the wheelchair was a visible indicator of a disability, for Barbara this was external to her body and therefore did not warrant any pity from others, and thus it could not negatively influence her dignity. Whereas the (prosthetic) legs were part of Barbara's embodied identity, the wheelchair was not; hence it was not a mediator of her dignity, despite being a clear marker of disability. It was the missing body parts that caused Barbara concerns she may lose her dignity, but wearing the prosthetics meant they both remained intact (her body and her dignity).

Somewhat paradoxically, when Barbara engaged in the social world outside her home, she wore 'sparkly Michael Kors [shoes], so people don't stare at me'. Her legs may have been 'fake' but her shoes were not. The juxtaposition between the 'realness' of Barbara's shoes and the 'fakeness' of her legs demonstrates the importance of bodily displays in reinforcing dignity in the face of stigma and internalised shame. As Barbara remained in her wheelchair, her footwear did not fulfil a traditionally functional purpose, but their aesthetics (and 'realness') contributed to Barbara's dignity. Barbara's shoes drew attention to her 'slim ankles', which potentially focused people's awareness on to the very area of her body that she stated she did not want others to view as different. 
In contrast, Barbara never wore her prosthetic legs when the nurses visited her at home, indicating that a 'dignity encounter' still remained possible in this context. In line with Lloyd et al. (2014), locational changes influenced Barbara's identity and sense of self as the prosthetics bestowed dignity in public spaces, but remained unnecessary in the private space of her home, including when nurses entered this space:

They [nurses] treat me like I've got legs. 'Cos they say, 'I wish we had something to write down Barbara, can't you just say you don't feel very well today?' (Laughing)

But they're so lovely. (Barbara, 77)

Although Barbara's dignity depended on her ability to portray a physically whole person in public, the home space offered an environment in which dignity could manifest without the necessity of prosthetics.

Barbara demonstrated power and agency in her own home, ensuring her dignity remained intact without the need for the addition of prosthetic legs. Yet, to maintain her dignity in public spaces it remained essential to conceal visible indicators of ill-health and display the whole body by wearing prosthetics. Barbara was, thus, acutely aware of the necessity to maintain at least a display of completeness in order to counteract both felt and/or enacted stigma (Scambler, 2004), indicating that embodied dignity manifests differently in public and private spaces. It was bodily frailty that had the potential to disrupt fundamentally the dignity of both Barbara and Lizzie, who was managing continence in her preferred way. However, they both demonstrated that a proactive approach to maintaining a sense of self and identity, be it through wearing 'double pads' or Michael Kors shoes, was a key method of maintaining dignity, sometimes despite the input of health-care professionals.

\section{Dignity in the home}

As previously stated, the home space constitutes a very particular environment of, and for, care. Martin-Mathews (2007) refers to home as a 'nexus of care', constituting a very different geographical space to the institutional settings within which formal care is most customarily undertaken. Indeed, formal care practices can fundamentally alter the meaning and experience of 'home' space (Cloutier et al., 2015). Here, we consider how the micro-aspects of relational care practices in the home can constitute the foundational elements of the dignity encounter.

\section{When 'private' becomes 'public'}

It's a strange relationship really [being a community nurse]. You get so used to people's homes. (Nurse-Victoria)

When community nurses enter people's homes, they perform a public service in what is, ordinarily, a private space. Complex dynamics come into play when someone's home becomes another person's workplace, as the boundaries of what is public and what is private begin to merge. Home, in this context, embodies multiple, and sometimes competing, meanings. For the person requiring care, the nurse- 
patient relationship demands a re-framing of what home means. Conversely, for the practitioner, home is simultaneously a clinical workspace, which assumes the guise of what Cloutier et al. (2015) refer to as a 'pseudo-institution' and another person's private domain. As one nurse-participant stated:

I think it is very, very hard because you are going into somebody's space, they're not coming into yours. (Nurse-Rina)

It is important to note that older adults can only access district nursing services if they are identified by nurses as 'housebound', resulting in very limited access to wider public spaces:

The only time I see what [name of city]'s like, is when I see it on the telly. I've never been in town, for 30 years. (Warren, 69)

Many older adults receiving community district nursing care may be unable to engage with their wider communities, such as Warren. This may be an isolating experience and, as people's worlds shrink, the home takes on greater significance. In this context it may be particularly important for older adults to retain control over what, when and how things happen in this space, thus retaining a sense of identity and independence. Recognising this fact, many nurse-participants regarded working in people's homes as a privilege:

You're going into their home ... they're letting you into their world and it's an absolute privilege. (Nurse-Denise)

Respect, therefore, for a person's home space is fundamentally a dignity-enhancing act:

In the community, you'd maintain dignity by, like you'd knock before you - if you didn't know somebody you don't just walk into the house, you'd wait to be invited. (Nurse-Victoria)

It is not only clinical activity that takes place within this home space, of course. Life goes on for other family members, who may continue with their tasks of daily living whilst community nurses undertake care practices in the home. However, for some older adults, the social contact offered by community nurses can be just as important as the clinical tasks they undertake:

Even if I'm having a really bad day I've always got a smile on my face for my patients because I think you have to, because I could be the only person they're seeing ... and I think as long as we have that in the back of our heads, that you could be that only contact ... to that patient ... I think that makes you a good [nurse]. (Nurse-Anya)

For some older adults, of course, visits from the nurses may be regarded as a disruption to daily routines, but, to others, nurses' visits can constitute a core 
component of their social activity that reinforces both their independence and social connection.

\section{'Environments of dignity' in the home}

When undertaking care in the home, community nurses must adapt to the routines and practices that are accepted within each individual's home, in contrast to an inpatient setting in which older adults' lives must adapt to the routines of the institution. Through careful use of space, nurses can co-create 'environments of dignity' in the home to support and enhance the dignity of older adults.

During fieldwork observations, it was usual to easily recognise indicators that a person was receiving nursing care. Lucy, however, was the only participant to have no observable nursing artefacts on display. Lucy received regular dressings for an abdominal wound, and, in her case, it was her bedroom that transformed into the 'home-clinic' during nursing visits.

As Nurse-Sheila and I entered her bedroom, Lucy motioned for me to sit on her velvet Louis XV Bergère chair, located in between an antique Cheval mirror draped in pearls and a walnut dressing table displaying vintage art deco perfume bottles. My eyes scanned the room for Nurse-Sheila's equipment, but I could not see anything other than a luxurious bedroom reflecting impeccable taste. As Lucy lay on her bed, Sheila opened the French blanket box at the end of the bed, delicately painted with pink roses.

'Aha, I wondered where your equipment was!' I remarked.

'I encourage them to store everything in a box - it makes it so much easier than being in a bag' replied Nurse-Sheila, while Lucy remained silent and still.

Sheila found the blanket box to be a more satisfactory storage solution than the plastic bags that were most commonly used by other older adults. She recognised using a box meant she could find her equipment more efficiently than rummaging through noisy plastic bags that often ripped. The benefits of the box were far greater than simply the ease it offered Sheila. This beautiful box concealed all evidence of any nursing artefacts, hiding them from view, ensuring the room retained normality in its primary function as a bedroom, thus creating, and maintaining, a visible 'environment of dignity'. Furthermore, it was easier for normality to resume once Pandora's clinical box was closed and visible reminders of Lucy's health condition were packaged away in the attractive blanket box, much like her stomach-wound which was visibly concealed by dressings. Lucy had sufficient social and cultural capital to ensure that her ill-health remained hidden when nurses were not present, not something available to all.

In contrast, Amber was 63 years old and lived in a Local Authority flat which had not been serviced for many years:

I can't really expect a lot in this room (laughs), 'cos it needs doing, like it does,

I can't expect too much [from the nurses]. (Amber, 63)

Amber seemed ashamed of her living conditions, a belief that seemed to subsequently lower her expectations of care. In this context, Amber's flat fell short, in 
her view, of being an 'environment of dignity' and, therefore, her own dignity expectations from the nurses remained low. Clearly, though, Amber's expectations of dignified care should not be diminished by her social and material circumstances. It is, then, incumbent upon nurses to create and uphold an environment of dignity regardless of the physical environment in which they are working.

If we return to consider Lizzie, her own determination in ensuring her home environment supported her dignity was demonstrated in one particular observation:

During today's visit, Lizzie insisted that the nurse and I enter her conservatory to see her wardrobe. From her seat in the kitchen, Lizzie shouted, 'open the [quadruple] cupboard doors'. Once opened, these revealed incontinence pads from top to bottom-hidden in plain sight. We both audibly gasped at the number of pads, before closing the door and then returning to join Lizzie in the kitchen.

'£200 that [wardrobe] cost me ... who on earth buys a wardrobe to go in their conservatory?' Lizzie asked, but without waiting for an answer she continued,

'But I needed to store my [incontinence] pads somewhere.'

In this context, the wardrobe was placed in an unexpected place in the home (a conservatory), and this reinforced its importance in concealing evidence of Lizzie's continence-needs, thus rendering the furniture an essential object in ensuring Lizzie's home remained, for her, an 'environment of dignity'.

When nurses enter the home to deliver nursing care, the purpose of the space adapts to accommodate the 'home-clinic' - the space within the home in which clinical interventions occur. Certain spaces in the home are more likely to be used in this manner, as nursing tasks are often performed in communal living areas. However, if the task involves intimate areas of the body, the privacy afforded by bedrooms is often employed as the 'home-clinic'. Thus, there are certain areas of the home that are more likely than others to become an 'environment of dignity':

It's not like the hospital when we strip 'em of their clothes and shove 'em in a bed. We have to deal with palliatives [sic] where they need a hospital bed downstairs and the family say 'no, we don't want our home looking like a hospital'. It's really hard sometimes. (Nurse)

This quote illuminates the tension between maintaining the home as a comfortable, and personal, space and its increasing function as a site for clinical activity. This balance is difficult, and sometimes impossible, to achieve. But, as we note above, maintaining this balance, whilst upholding the fundamental dignity of the person requiring care, is a central task of district nursing care practice.

At 60 years old, Olive was the youngest participant in this study. Nurses attended her twice daily to administer insulin, and two different nurses (Mary and Daisy) were observed delivering this care. In Olive's home, the nurses' feet became symbolic markers of important dignity considerations, through the use, and non-use, of shoe covers.

Immediately inside Olive's hallway was a box containing plastic shoe covers. When Nurse-Mary entered the hall, she immediately adorned shoe covers before progressing into the lounge where Olive was seated. In contrast, Nurse-Daisy always 
strode into the lounge without covering her shoes. Mary and Daisy's differing actions were indicative that their behaviours were under their own control, rather than the jurisdiction of the older adult, but were also representative of the many different behaviours nurses adopt when entering older adults' homes. Individuals follow different cultural practices in their own homes, yet, if nurses do not consider the cultural scripts of older adults' home spaces, tensions may occur and creating an 'environment of dignity' will be problematic, as was recognised by Nurse-Mary:

Interviewer: [What] can have any influence over dignity?

Nurse-Mary: Their personal environment ... I quite often, sometimes cringe a little bit to myself when I go in someone's house and we're not allowed to remove our shoes ... and if they don't sort of - if they're not a known person to us and we [don't] have shoe covers ... sometimes I kind of think, 'do I look rude?' And I feel like I need to say ... erm, 'do you mind if we come in with my shoes on?', even though I'm sort of half walking in ... and I feel like I need to kind of address it ... because it's like manners as well. I sometimes sort of think, if someone walked into my house and just started walking through on the carpets, I'd probably be like you know (said sarcastically), 'keep your shoes on if you like'. It's a bit rude I think, so ... sometimes that makes me feel a bit ... cringy.

During Mary's interview, it was apparent she had reflected on wearing shoe covers, as she explained this was a conscious act to show Olive that she respected her property. By extension, showing respect for the flat extended to respecting Olive's dignity. In this context, shoe covers became symbolic indicators of (in)dignity.

\section{Discussion}

The concept of dignity is core to community district nursing practice, yet it is profoundly complex with multiple meanings and interpretations. Dignity does not exist absolutely, but is, we suggest, (de)constructed through and within the mundane clinical and social interactions that take place between community nurses and the older adults with whom they work.

The experience of participants in this study suggests that dignity, in the context of community district nursing practice, is co-created across two interrelated planes, the geographical and the relational. Further, that it is the micro-, and arguably mundane, aspects of care practice in the home that constitute the foundations for the dignity encounter in both these contexts. We have demonstrated this through three interrelated themes: dignity in relationships, embodied dignity and dignity in the home.

It is mundane and everyday aspects of care that demonstrate how dignity encounters can be achieved. Data obtained from observations and interviews facilitated a nuanced understanding and illuminating exploration into how dignity manifests in routine elements of district nursing care, highlighting the significance that often unnoticed care practices have on dignity outcomes. Dignity is a fluid and 
dynamic concept, and older age is a potential risk factor that allows for possible violations of dignity, but through successful caring relationships, care for the body and respecting the home, community nurses can uphold and promote the dignity of older adults.

Mundane aspects of relational care may initially appear inconsequential, however, it is precisely here where dignity can manifest. The micro-context of relationships can facilitate the 'dignity encounter' and, as Jacobson (2009: 1538) noted, 'any human interaction can be a dignity encounter'. Therefore, when any nurse and older adult come into contact, there is the potential for a 'dignity encounter' to unfold. A 'dignity encounter' follows when standards of mutually acceptable behaviours and attitudes are demonstrated by the nurse and older person. Yet, if either person enacts behaviours that the other regards as undesirable, a climate is created in which dignity is more readily reduced and possibilities for constructing dignity become problematic.

Moreover, dignity can be regarded as an embodied experience as bodyworkers, such as community nurses, have the potential to underpin dignity through physical contact with older adults, in addition to via relational aspects of care. A challenge to older adults' dignity may arise when there are conflicts between their own bodysubject experiences of dignity and nurses' medical understanding of the most appropriate treatment of the body-object. Nurses work in the context of evidencebased practice in terms of clinical effectiveness, however, this can challenge or threaten dignity if it conflicts with the manner in which some older adults maintain their identity, autonomy and sense of self; as in the case of Lizzie who refused to relinquish agency over her body when she managed continence in her preferred way and declined any active treatment for cancer. Thus, dignified care can enable dignity of identity (Nordenfelt, 2004). The enactment of care based solely on bodyobject principles dehumanises older adults, whereas dignity manifests through relational aspects of care in which body-subject experiences are validated, valued and reinforced.

It is precisely at the point at which nurse and older adult come together, often in the context of body failure, where the potential for creating a dignity encounter, and its corollary, a loss of dignity, is most acute. For older adults, it is the combined effects of age, illness and disability that can fundamentally call into question a sense of self and which demand sensitive, skilled and emotionally intelligent care to ensure a person's dignity is maintained (Lloyd et al., 2014). An example of this, in this study, would be in the context of the 'leaky body' which constitutes a very particular pinch point in the nurse-older person interaction. Bodily odours are normal, and ill bodies often smell. But whereas ill bodies may be normal for the nurse, they may not be normal for the older person, and, for many older adults, the potential for their own bodies to be malodourous was identified as a significant risk to dignity. Social expectations reinforce and stigmatise bodily malodour, further threatening the quality of the 'dignity encounter'.

The negotiations, both physical and relational, required to ensure positive dignity encounters occur in the home space, requiring the need for delicate negotiation on behalf of both the nurse and older adult (Cloutier et al., 2015), as exemplified by Nurse-Mary using shoe-covers to demonstrate respect for the home and accordingly respect for her patient's dignity. 


\section{Concluding comments}

A significant proportion of health care in the UK occurs outside institutional settings, in the community. As such, the role of the community nurse sits at the centre of a complex framework of care provision. This framework is predicated upon a health policy context that prioritises the maintenance of independence, agency and autonomy. Achieving this whilst balancing the competing priorities of necessity, sensitivity and dignified care practices is profoundly challenging.

The micro-relations between older people and community nurses can thus mirror macro-considerations of dignity and broader policy imperatives (Cloutier et al., 2015). Nurses and older adults have opportunities to (de)construct dignity in their relationships, through caring for the body and through the ways care is delivered in the home. Dignity, though, remains entirely subjective. Individuals experience dignity differently, and it can be displayed and operationalised in many ways. Most importantly, dignity, when present, often remains implicit and unacknowledged. The 'dignity encounter' manifests, seemingly with little thought, effort or formal negotiations, through a combination of tacit knowledge and secure relationships. This paper's exploration into some of the micro-aspects of care delivery in the home has revealed how dignity remains of fundamental importance for older adults and community district nursing teams. It is central to the key aims of clinical care, whilst also simultaneously seeking to support older people's autonomy, agency and identity (Holmberg et al., 2012). This generates a sometimes uneasy duality for both practitioner and patient (Holmberg et al., 2012; Lloyd et al., 2014).

It is, we would suggest, within this duality, in the complex relationship between necessity, obligation, sensitivity and respect, that the dignity encounter exists. It is, however, in the tacit, the ordinary, the 'everyday' that dignity, for the participants in this study, is most profoundly manifested and experienced. Dignity, in this context, is determinedly unremarkable and unexceptional. It is embedded in relational, everyday, care practices. This paper has focused on these micro-relational aspects of care in an attempt to elucidate how dignity manifests in community nursing contexts (the home space) rather than, as is more customary, to demonstrate the effects of its absence (in its most extreme, abuse and maltreatment). We conclude, therefore, by underlining the point that the 'mundane matters' (Enloe, 2011: 447) and that, for those providing care in community contexts, valuing the 'everyday' enables a recognition of just how remarkable the mundane can be.

Financial support. This work was supported by the University of Hull (ES, PhD scholarship).

Author contributions. ES was the ethnographer, supervised by EP and EW. All authors contributed to data analysis, conceptualisation and writing of the paper.

Ethical standards. Ethical approvals for the study were received from the University of Hull, Faculty of Arts and Social Sciences on 23 June 2016 and Yorkshire and the Humber - South Yorkshire NHS Research Ethics Committee on 13 March 2017 (reference 17/YH/0009; IRAS ID: 21677).

\section{References}

Adler P and Adler P (1987) Membership Roles in Field Research. Newbury Park, CA: Sage.

Agich GJ (2007) Reflections on the function of dignity in the context of caring for older people. Journal of

Medicine and Philosophy 32, 483-491.

Arendt H (1958) The Human Condition. Chicago, IL: University of Chicago Press. 
Baillie L (2009) Patient dignity in an acute hospital setting: a case study. International Journal of Nursing Studies 46, 23-37.

Barclay L (2016) In sickness and in dignity: a philosophical account of the meaning of dignity in health care. International Journal of Nursing Studies 61, 136-141.

Black K and Dobbs D (2014) Community-dwelling older adults' perceptions of dignity: core meanings, challenges, supports and opportunities. Ageing \& Society 34, 1292-1313.

Braun V and Clarke V (2006) Using thematic analysis in psychology. Qualitative Research in Psychology 3, 77-101.

Braun V and Clarke V (2013) Successful Qualitative Research: A Practical Guide for Beginners. London: Sage.

Buse C, Martin D and Nettleton S (2018) Conceptualising 'materialities of care': making visible mundane material culture in health and social care contexts. Sociology of Health and Illness 40, 243-255.

Charles A, Ham C, Baird B, Alderwick H and Bennett L (2018) Reimagining Community Services: Making the Most of Our Assets. Available at https://www.kingsfund.org.uk/publications/community-services-assets.

Clancy A, Simonsen N, Lind J, Liveng A and Johannessen A (2021) The meaning of dignity for older adults: a meta-synthesis. Nursing Ethics 28, 878-894.

Cloutier DS, Martin-Matthews A and Byrne K (2015) The space between: using 'relational ethics' and 'relational space' to explore relationship-building between care providers and care recipients in the home space. Social \& Cultural Geography 16, 764-782.

Cornwell J (2012) The Care of Frail Older People with Needs: Time for a Revolution. King's Fund, The Sir Roger Bannister Health Summit, Leeds Castle. Available at http://www.kingsfund.org.uk/sites/files/kf/ field/field_publication_file/the-care-of-frail-older-people-with-complex-needs-mar-2012.pdf.

Dixon L and Thompson $\mathbf{H}$ (2018) The role of the district nurse in caring for patients with dementia. British Journal of Community Nursing 23, 348-353.

Dyck I, Kontos P, Angus J and McKeever P (2005) The home as a site for long-term care: meanings and management of bodies and spaces. Health and Place 11, 173-185.

Enloe C (2011) The mundane matters. International Political Sociology 5, 447-450.

Fenton E and Mitchell T (2002) Growing old with dignity: a concept analysis. Nursing Older People 14, 19-21.

Franklin L, Ternestedt B and Nordenfelt L (2006) Views on dignity of elderly nursing home residents. Nursing Ethics 13, 130-146.

Guba EG (1981) Criteria for assessing the trustworthiness of naturalistic inquiries. Educational Communication and Technology 29, 75-91.

Hall S, Dodd RH and Higginson IJ (2014) Maintaining dignity for residents of care homes: a qualitative study of the views of care home staff, community nurses, residents and their families. Geriatric Nursing 35, 55-60.

Hewison A (2011) Dignity as a policy issue in healthcare. In Matiti MR and Bailey L (eds). Dignity in Healthcare: A Practical Approach for Nurses and Midwives. London: Routledge, chap. 4, pp. 37-27.

Holmberg M, Valmari G and Lundgren SM (2012) Patients' experiences of homecare nursing: balancing the duality between obtaining care and to maintain dignity and self-determination. Scandinavian Journal of Caring Sciences 26, 705-712.

Horton R (2004) Rediscovering human dignity. The Lancet 364, 1081-1085.

Høy B, Wagner L and Hall E (2007) The elderly patient's dignity: the core value of health. International Journal of Qualitative Studies on Health and Well-being 2, 160-168.

Jacobson N (2009) Dignity violation in healthcare. Qualitative Health Research 19, 1536-1547.

Johnson PR (1998) An analysis of dignity. Theoretical Medical Bioethics 19, 337-352.

Kalb K and O'Conner-Von S (2007) Respect for human dignity. Ethics Education in Advanced Practice Nursing 28, 196-202.

King's Fund (2019) Community Health Services Explained. Available at https://www.kingsfund.org.uk/publications/ community-health-services-explained.

Lloyd L, Calnan M, Cameron A, Seymour J and Smith R (2014) Identity in the fourth age: perseverance, adaptation and maintaining dignity. Ageing \& Society 34, 1-19.

Lundgren SM, Holmberg M, Valmari G and Skott C (2011) Home care encounters in a multicultural context - a diverse space for caring. International Journal for Human Caring 15, 23-30.

Macklin R (2003) Dignity is a useless concept: it means no more than respect for persons or their autonomy. British Medical Journal 327, 1419-1420.

Markel-Reid M, Weir R, Browne G, Roberts G, Gafni A and Henderson S (2006) Health promotion for frail older home care clients. Journal of Advanced Nursing 54, 381-395. 
Martin-Matthews A (2007) Situating 'home' at the nexus of the public and private spheres: ageing, gender and home support work in Canada. Current Sociology 55, 229-249.

Martin-Matthews A, Sims-Gould J and Tong E (2013) Canada's complex and fractionalised home care context: perspectives of workers, elderly clients, family carers, and home care managers. Canadian Review of Social Policy 68-69, 55-74.

Maybin J, Charles A and Honeyman M (2016) Understanding Quality in District Nursing Services: Learning from Patients, Carers and Staff. Available at http://www.kingsfund.org.uk/publications/quality-district-nursing.

McDermott-Levy R, Leffers J and Mayaka J (2018) Ethical principles and guidelines of global health nursing practice. Nursing Outlook 66, 473-481.

Michael L (2014) Defining dignity and its place in human rights. The New Bioethics 20, 12-34.

Milligan C (2009) There's No Place Like Home: People, Place and Care in an Ageing Society. Aldershot, UK: Ashgate.

Morris H (2017) Reinstating district nursing: a UK perspective. Nurse Education in Practice 26, 59-63.

Mullen RF, Kydd A, Fleming A and McMillan L (2019) Dignity in nursing care: what does it mean to nursing students? Nursing Ethics 26, 390-404.

National Statistics (2019) English Indices of Deprivation 2019. Available at https://www.gov.uk/government/statistics/english-indices-of-deprivation-2019.

Nettleton S, Burrows R and O'Malley L (2005) The mundane realities of the everyday lay use of the internet for health, and their consequences for media convergence. Sociology of Health and Illness 27, 972-992.

Nordenfelt L (2004) The varieties of dignity. Healthcare Analysis 12, 69-81.

Nordenfelt L (2009) Dignity in Care for Older People. Ames, IA: Wiley-Blackwell.

Quaile A (2018) Put resources into district nursing and reduce strain on the NHS. British Journal of Community Nursing 23, 186-187.

Raee Z, Abedi H and Shahriari M (2017) Nurses' commitment to respecting patient dignity. Journal of Education and Health Promotion 6, 2-7.

Rehnsfeldt A, Lindwall L, Lohne V, Lillestø B, Slettebø ÅT, Heggestad AK, Aasgaard T, Råholm M, Caspari S, Høy B, Sæteren B and Nåden D (2014) The meaning of dignity in nursing home care as seen by relatives. Nursing Ethics 21, 507-517.

Šańáková Š and Čáp J (2019) Dignity from the nurses' and older patients' perspective: a qualitative literature review. Nursing Ethics 26, 1292-1309.

Scambler G (2004) Re-framing stigma: felt and enacted stigma and challenges to the sociology of chronic and disabling conditions. Social Theory and Health 2, 29-46.

Spilsbury K and Pender S (2015) A changing landscape: mapping provider organisations for community nursing services in England. Journal of Nursing Management 23, 128-138.

Tadd W, Hillman A, Calnan S, Calnan M, Bayer T and Read S (2011a) Dignity in Practice: An Exploration of the Care of Older Adults in Acute NHS Trusts. Available at http://www.panicoa.org.uk/ panicoa-studies/dignity-practice.

Tadd W, Hillman A, Calnan S, Calnan M, Bayer T and Read S (2011b) Right place - wrong person: dignity in the acute care of older people. Quality in Ageing and Older Adults 12, 33-43.

Taylor BJ, Rush KL and Robinson CA (2015) Nurses' experiences of caring for the older adult in the emergency department: a focused ethnography. International Emergency Nursing 23, 185-189.

Temmink D, Francke AL, Hutten JB, van der Zee J and Abu-Saad HH (2000) Innovations in the nursing care of the chronically ill: a literature review from an international perspective. Journal of Advanced Nursing 31, 1449-1458.

Tranvåg O, Petersen KA and Nåden D (2015) Relational interactions preserving dignity experience: perceptions of persons living with dementia. Nursing Ethics 22, 577-593.

Tranvåg O, Synnes $\mathbf{O}$ and McSherry W (eds) (2016) Stories of Dignity Within Healthcare: Research, Narratives and Theories. Keswick, UK: M and K Publishing.

Turner VW (1967) The Forest of Symbols: Aspects of Ndembu Ritual. Ithaca, NY: Cornell University Press. Twigg J (2000) Bathing - The Body and Community Care. London: Routledge.

Webster C and Bryan K (2009) Older people's views of dignity and how it can be promoted in a hospital environment. Journal of Clinical Nursing 18, 1784-1792.

Cite this article: Stevens E, Price E, Walker E (2023). Making the mundane remarkable: an ethnography of the 'dignity encounter' in community district nursing. Ageing \& Society 43, 745-767. https://doi.org/ $10.1017 /$ S0144686X21000738 